\title{
Perennial Regulation Optimization of the Jinxiuchuan Reservoir with Multi-objects
}

\author{
Ke Kong ${ }^{1, a^{*}}, X_{\text {in Cong }}^{2, b}$, and Zhenghe $\mathrm{Xu}^{3, \mathrm{c}}$ \\ ${ }^{1}$ University of Jinan, Jinan, Shandong Province, China \\ akoker@sohu.com, bcongxin1994@126.com, ’Xu4045@126.com
}

Keywords: Multi-levels operation figure; Multi-objects; Optimization; Perennial regulation; Jinxiuchuan reservoir

\begin{abstract}
The ordinary operation figure for perennial regulation reservoir with many objects has many shortcomings such as random runoff, overlapping operation areas and so on. This paper establishes a multi-levels operation figure for the Jinxiuchuan reservoir in Jinan city to meet the different water users. Using chronological method a series of arid year is selected to calculate the water supply limited line and control failure line which respectively concerns the part of and all of water supply demands, and then the comprehensive failure control line which take enhanced power generation into account. A serial of annual runoff is used to validate this multi-levels figure and the results show that compared to the ordinary way the guarantee rate of irrigation rises from $75 \%$ to $77 \%$, municipal supply from $74 \%$ to $90 \%$, and generation from $90 \%$ to $91 \%$, which indicate that this study can optimize the operation of this kind of reservoir.
\end{abstract}

\section{Introduction}

The regulation of reservoir is based the income runoff and water demand. Because the long term hydrology forecasting is not mature yet, the operation figure is ordinarily used as an objective rule for the reservoir's water release in order to use water resources efficiently with certain safety[1]. The operation of multi-objective reservoirs must think about many water supply tasks, such as irrigation, municipal water supply, environment protection, flood prevention, power generation, and so on. Such different aims usually have conflicts and compete for each other, and they all want to get more benefits and little risk. Many advanced methods are promoted to optimize the operation of multi-objectives reservoirs[2-6]. For the reservoirs both have multi-objectives and perennial regulation property, ordinary operation figure has many shortcomings such as random runoff, overlapping operation areas and so on. So the multi-levels operation figure is useful to help such reservoirs make rational release decision.

This study consults the method promoted by Ping Wang[7-9], develop a multi-level operation figure for the optimal operation of the Jinxiuchuan reservoirs. Using long serial of annual runoff the method thinks about the lowest limitation of agricultural and municipal water supply at first, and then successively thinks over the whole need of such two kinds of water supply demand and power generation demand to draw different level operation lines which consists the operation figure combing with the flood control line. The fine regulation effect is validated compared with the effects made by ordinary operation ways.

\section{Long Term Optimal Operation}

Basic Method of Runoff Regulation. The reservoir operation changes the nature runoff in rivers through storing and release water in some scheme, so it is a kind of runoff regulation. There are two main types of runoff regulation methods: statistics method and chronological method. Both in the practice and theory of reservoirs operation, the chronological method is widely used[10]. In this method the runoff series sequentially is arrange according to the actuate data to carry out reservoir regulation 
calculation. It is implied that the past runoff can be used to represent the future runoff. The method for multi-levels operation figure in this study is also based on chronological method.

Method of Multi-Levels Operation Figure. Different tasks of multi-objects reservoir have different significance, so multi-levels operation figure is needed to help reservoirs meet with multi-tasks. In this study the multi-levels figure has 4 basic operation lines: water supply limited line, supply control failure line, comprehensive control failure line and the flood control level line. The flood control level line which defines the flood limited water level during flood period is decided with dead water line which defines the lowest water level in anytime when the reservoir has been designed. The other 3 line can be calculated use chronological method as follow steps:

(1) Select annual runoff series: For a long term reservoir regulation, we can't use one typical hydrology runoff to carry out chronological method which is only suitable for annual reservoir regulation, so a series of annual runoff must be chosen. From the point of safety, a continuous arid year should be selected.

(2) Draw water supply limited line: When the runoff into reservoir is little, it is first calculated a lowest water demand for the most important water supply task. Because the dead water line and flood control level line are already present, they make up a simplest operation figure. Using this initial figure as operation rule, the reservoirs water levels needed for guarantee this lowest water demand in every month are calculate in reverse chronological turn based the selected runoff series. Taking the highest water level in every month every year, a water supply limited line is obtained.

(3) Draw supply control failure line: Now the supply limited line is added to the initial figure in step(2). Using this figure the reservoirs water levels in every month needed for guarantee all water supply demand in designed guarantee rate are calculated and the control failure line is get in the same way of step(2). This line represents the decision limit in ordinary hydrology year

(4) Draw comprehensive control failure line: Taking the supply control failure line into the operation figure used in step(3), we get a more complex figure. Raising the power generation to a more benefit level, another water level lines could be obtained using the same way as step(3). Now the three calculated lines and the flood control line make up a multi-levels operation figure. This line coordinates the case of plentiful water resources.

\section{Case Study}

According to the drawing of multi-levels operation figure of Jinxiuchuan reservoir, the study explains that applicability of multi-levels operation figure on perennial regulation and multi-objects water supply reservoirs.

Jinxiuchuan reservoir is the multi-function hydraulic engineering which for flood control, irrigating, urban water supply, ecological water compensation, generating electricity. We have known the runoff data which from 1984 to 2013, and domestic, irrigation water capacity monthly, storage capacity versus elevation curve, the normal storage level of the reservoir is $251 \mathrm{~m}$, the dead storage level is $225 \mathrm{~m}$, in the flood period which from June to August, the storage level of reservoir isn't more than $248.5 \mathrm{~m}$; the installed gross capacity of power station is $520 \mathrm{KW}$, guaranteed output is 330 thousand $\mathrm{KW}$, annual energy output is 1716 thousand $\mathrm{KW}^{*} \mathrm{~h}$, annual average equivalent using hours is $3300 \mathrm{~h}$, the design dependability of power station is $90 \%$, its force-voltage factor is 8.21 .

Multi-levels Operation Figure Drawing. Analysis and calculating about the storage reservoir data of thirty years have proved that 2000 is wet year, 2001 and 2002 are dry years, 2003 is wet year, so select the flat-dry-dry-abundance of four years. Segment as the representative of the drawing section of the scheduling diagram, including two consecutive years of low-level selection guarantee contains the most unfavorable situation, so as to ensure accuracy and improve operation efficiency. All the adjustments calculations are calculated according to the hydrological year, and the results are shown in Table 1. 
Table 1 Operation result table

\begin{tabular}{ccccc}
\hline period & $\begin{array}{c}\text { water supply } \\
\text { limited line }[\mathrm{m}]\end{array}$ & $\begin{array}{c}\text { supply control } \\
\text { failure line }[\mathrm{m}]\end{array}$ & $\begin{array}{c}\text { comprehensive control } \\
\text { failure line }[\mathrm{m}]\end{array}$ & $\begin{array}{c}\text { flood control } \\
\text { level }[\mathrm{m}]\end{array}$ \\
\hline 7 & 234.61 & 236.96 & 246.50 & 248.50 \\
8 & 235.12 & 239.98 & 247.52 & 248.50 \\
9 & 235.78 & 242.12 & 250.93 & 250.80 \\
10 & 236.60 & 243.56 & 251.00 & 251.00 \\
11 & 237.54 & 244.09 & 251.00 & 251.00 \\
12 & 238.11 & 244.14 & 251.00 & 251.00 \\
1 & 238.09 & 243.77 & 251.00 & 251.00 \\
2 & 238.29 & 243.56 & 251.00 & 251.00 \\
3 & 237.78 & 243.12 & 250.30 & 251.00 \\
4 & 237.00 & 242.05 & 249.36 & 251.00 \\
5 & 235.98 & 240.65 & 248.50 & 249.90 \\
6 & 234.70 & 238.88 & 248.41 & 248.50 \\
\hline
\end{tabular}

The drawing result of the dispatching line is shown as in Fig. 1.

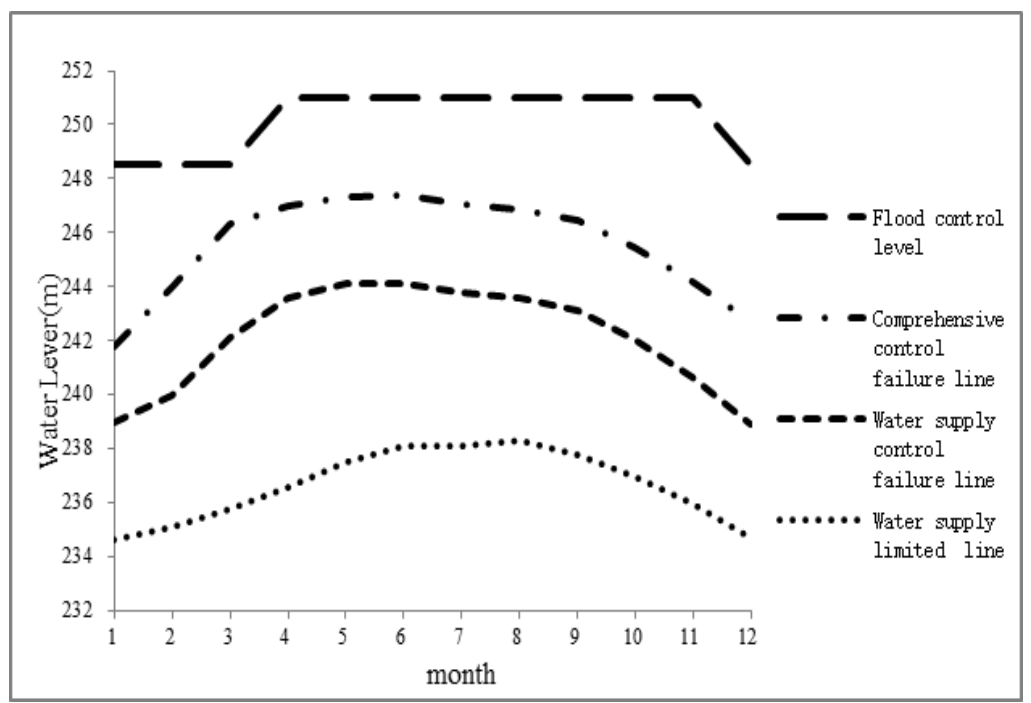

Figure 1. Multi-levels operation figure

Operation Calculation. The conventional runoff regulation and multistage operation figure regulation were used respectively for regulation calculation in Jinxiuchuan reservoir. We selected the hydrological year from 1984 to 1986 for regulation calculation. The specific regulation calculation process is shown as in Fig. 2. The result of the different target water supply guarantee rate by two different computational methods is shown as in Table 2.

Where, i denotes time, and the unit is month; wl, wl1, wl2, wl3, wl4 are the actual water level and flood control level and comprehensive control failure line and water supply control failure line and water supply limited line, respectively; Nmax, N1, N2, N are maximum output and increased output and guaranteed output and inter generation capacity, respectively; We, Ws, W are the water consumption of power and surplus water and actual water quantity, respectively; V, V1 are the reservoir capacity and the beneficial capacity, respectively; $r$ denotes runoff; $a, b, c$ are the number of achieving the requirement of the water supply, irrigation and power generation guarantee rate; $\mathrm{Pa}, \mathrm{Pb}, \mathrm{Pc}$ are its water supply guarantee rate, respectively. 
Table 2 Comprehensive reservoir operation results

\begin{tabular}{|c|c|c|c|c|}
\hline computational method & $\begin{array}{c}\text { irrigation } \\
\text { guarantee rate }[\%]\end{array}$ & $\begin{array}{c}\text { water supply } \\
\text { guarantee rate [\%] }\end{array}$ & $\begin{array}{l}\text { power generation } \\
\text { guarantee rate }[\%]\end{array}$ & $\begin{array}{c}\text { annual power } \\
\text { generaton } \\
\text { capacity }\left[\mathrm{KW}^{*} \mathrm{~h}\right]\end{array}$ \\
\hline $\begin{array}{l}\text { Conventional runoff } \\
\text { regulation }\end{array}$ & 75 & 74 & 90 & 93.63 \\
\hline $\begin{array}{l}\text { Multistage operation } \\
\text { figure regulation }\end{array}$ & 77 & 90 & 91 & 100.64 \\
\hline
\end{tabular}

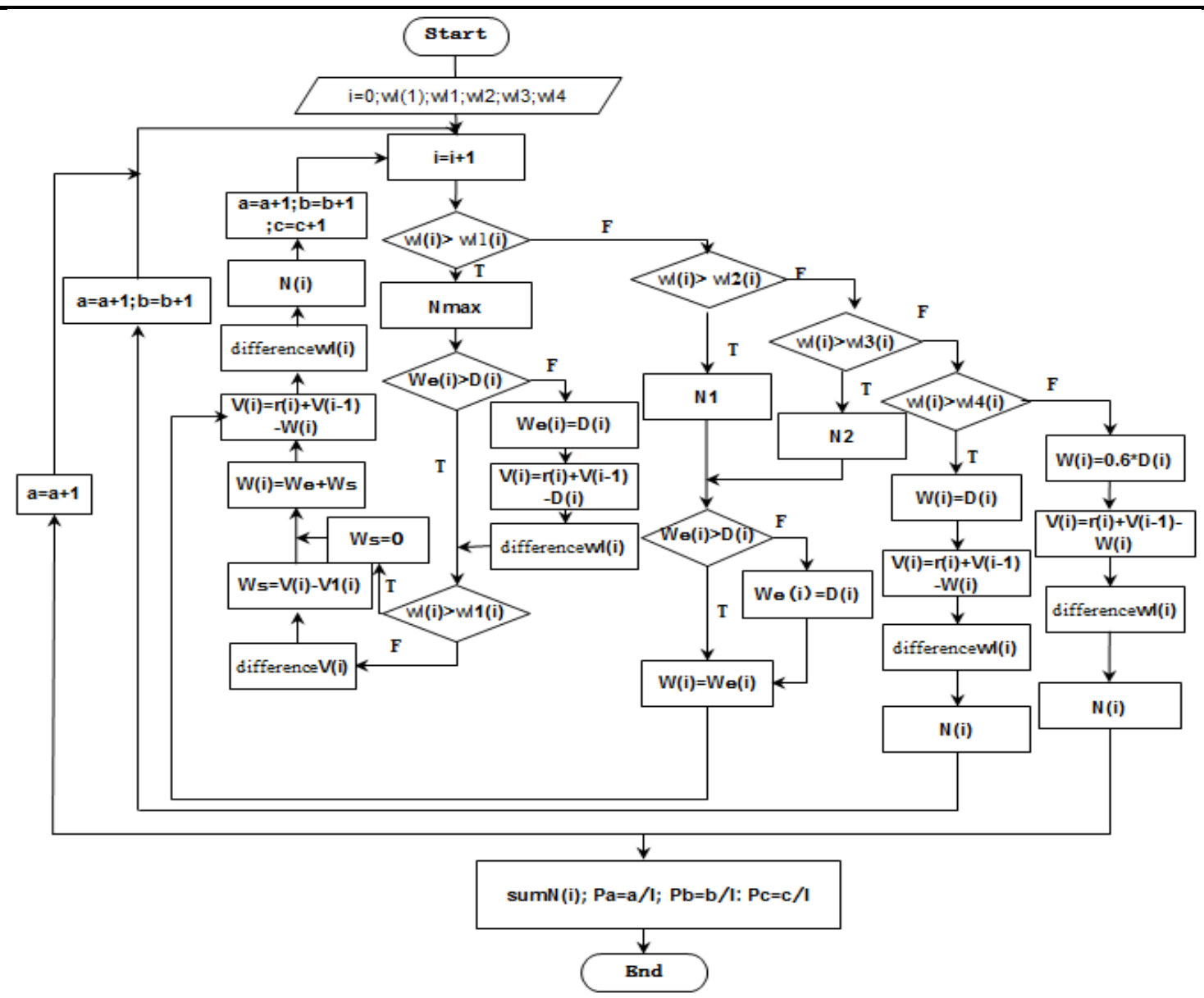

Figure 2. Multistage operation figure

Table 2 shows the operation results for the Jinxiuchaun reservoir in two different computational methods. After the calculation, irrigation design guarantee rate increased from $75 \%$ to $77 \%$; water supply guarantee rate increased from $74 \%$ to $90 \%$; power generation guarantee rate increased from $90 \%$ to $91 \%$; annual power generation capacity increased from $93.63 \mathrm{KWh}$ to $100.64 \mathrm{KWh}$. In summary, we ensure that Jinxiuchuan reservoir can better complete the task of comprehensive water supply reservoir and improve water utilization and water supply guarantee rate after multi-objective scheduling.

\section{Conclusion}

For the perennial regulation of reservoirs which have multiple water supply tasks, it is difficult to make efficient release scheme only use ordinary operation methods. This paper establishes a multi-levels operation figure including 4 basic operation lines: water supply limited line, supply control failure line, comprehensive control failure line and the flood control level line for the Jinxiuchuan reservoir in Jinan 
city. This operation figure can make the reservoirs deal with different water resource situation hierarchically, so that the operation is more effective. A serial of annual runoff is used to calculate the long term operation effect and to validate this multi-levels figure. the results show that compared to the ordinary way the guarantee rate of irrigation rises from $75 \%$ to $77 \%$, the guarantee rate of municipal supply rises from $74 \%$ to $90 \%$, and the guarantee rate of generation from $90 \%$ to $91 \%$. This study indicates that this multi-levels operation method can optimize the operation of this kind of reservoir.

\section{Acknowledgements}

This paper is supported by Shandong nature science fund (ZR2012DL08) and Shandong major water resources science research and technology promotion project (SDSLKY201314, SDSLKY201308, SDSLKY201410).

\section{References}

[1] C.T. Cheng, F.Y. Yang, X.Y. Wu, H.Y. Su: Link the simulation with dynamic programming successive approximations to the study on optimal operation chart of cascade reservoirs, Hydroelectr Eng, Vol. 29 (2010) No.6, p.71.

[2] Bahram Malekmohammadi, Banafsheh Zahraie, Reza Kerachian: Ranking solutions of multi-objective reservoir operation optimization models using multi-criteria decision analysis, Expert Systems with Applications, Vol. 38 (2011) No.6, p.7851.

[3] F.L. Yang, X.F. Zhang: Preliminary Study on Reservoir Multi-objective Scheduling Model considering Ecological Regulation, Procedia Environmental Sciences, Vol. 13 (2012), p.928.

[4] Chih-Sheng Lee. Multi-objective game-theory models for conflict analysis in reservoir watershed management, Chemosphere, Vol. 87 (2012) No.6, p.608.

[5] A. Tilmant, E.H. Faouzi, M. Vanclooster: Optimal operation of multipurpose reservoirs using flexible stochastic dynamic programming, Applied Soft Computing, Vol. 2 (2002) No.1, p.61.

[6] Y.P. Wu, J. Chen: Estimating irrigation water demand using an improved method and optimizing reservoir operation for water supply and hydropower generation: A case study of the Xinfengiiang reservoir in southern China, Agricultural Water Management, Vol. 116 (2013) No.6, p.111.

[7] Pin Wang: Improvement of compiling method for operation chart about comprehensive utilization of reservoir, Hydropower Station Designed, Vol. 30 (2014) No.4, p.51.(in Chinese)

[8] Pin Wang: Improvements for the Runoff Regulation Method of Urban Water Supply Reservoir, Yellow River, Vol. 36 (2014) No.4, p.22.(in Chinese)

[9] Pin Wang. Improved calculation method for hydro energy of small hydropower plants mainly for irrigation. Advances in Science and Technology of Water Resources, Vol. 34 (2014) No.2, p.46.(in Chinese)

[10]Rui Zhang, Shuangyin Wang: Water conservancy and waterpower utilization planning (China Water \& Power Press, China 2014,p.55). 